\title{
COVID-19. WHO CAN HELP US?
}

\author{
Igor Klepikov*1凶
}

${ }^{* 1}$ MD, Professor, Research and Clinical Trials on Acute Pneumonia Were Conducted During the Author's Work at The Novokuznetsk State Institute of Postgraduate Training of Doctors (USSR), The Author is Currently Retired and Resides in the United States

\section{DOI: https://doi.org/10.29121/granthaalayah.v8.i10.2020.2066}

\section{Article Type: Research Article}

Article Citation: Igor Klepikov. (2020). COVID-19. WHO CAN HELP US? International Journal of Research -GRANTHAALAYAH, 8(10), 298-303. https://doi.org/10.29121/granthaa layah.v8.i10.2020.2066

Received Date: 16 October 2020

Accepted Date: 31 October 2020

Keywords:

Covid-19

Who

Help

\section{ABSTRACT}

The COVID-19 pandemic has disrupted the usual rhythm of our lives, becoming a surprise, a serious problem and a great challenge for all segments of society, but the prospects for overcoming this situation and returning to previous social standards remain unclear. Cautious and uncertain forecasts of specialists even for the near future and daily updates in the media of the number of infected and dead sow a sense of anxiety, and medical confessions about the lack of effective treatment create a sense of insecurity.

\section{INTRODUCTION}

Suddenly, a complex epidemic and clinical situation has emerged, in which many non-standard patients have appeared, and the aggregate of opinions about their treatment is reduced to the conclusion that there are no specific medical measures, as well as expectations and hopes for the development and production of effective antiviral drugs. Meanwhile, treatment of patients with coronavirus is currently limited to symptomatic and auxiliary means. This passive-expectant attitude has its own deep reasons and, in my opinion, does not stand up to criticism if we rely on well-known facts.

Today we know that the severity and danger of coronavirus infection is primarily due to the development of acute inflammation in the lungs, and the localization and pathological nature of the lesion [1], [2] correspond to the standard nosology, which is known in medicine as acute pneumonia (AP) for more than two and a half millennia [3]. Although there is a new terminology "COVID-19 pneumonia" [4], but in fact, the pandemic did not bring any new disease. Inflammatory damage to a particular structure, regardless of the pathogen, is inevitably accompanied by a violation of its unique function. This is an axiom of life of biological objects and medicine. For example, if there is an inflammation of the eye, it will be accompanied by visual impairment, but not hearing loss, right?

Of the five classic signs of inflammation, it is the violation of the function of the affected organ that determines the features of the pathogenesis and clinic of each disease. However, ideas about the nature of AP have been significantly distorted over the past few decades under the hypnotic influence of antibiotic use. The result is a narrow

(C) 2020 The Author(s). This is an open access article distributed under the terms of the Creative Commons Attribution License, which permits unrestricted use, distribution, and reproduction in any medium, provided the original author and source are credited. 
view on the decisive role of the pathogen in all aspects of the development and course of AP and learned the main focus of therapeutic efforts to suppress microbial factor.

Such narrow principles of AP treatment are deeply ingrained in the theory and practice of medical training. A number of important facts that characterize the characteristics of antibiotics and stable traditions of their use do not receive due attention. For example, it is well known that antibiotics have only an antimicrobial effect and do not directly affect the inflammatory process and the cascade of disorders occurring in the body. Or, for example, the use of one type of antibiotics as the main (!) treatment not only for AP, but also for many incomparable inflammatory diseases should have attracted the attention of specialists long ago due to its illogical nature from the point of view of clinical medicine.

The old widespread principle of treating AP, which was called "antibiotics alone", has lost its broad independence in recent years, and the number of patients requiring additional care has steadily increased. As a result, experts began to recognize such undoubted facts as the validity of the empirical use of antibiotics (although this choice prevailed from the moment of their appearance), the lack of reliable information about the pathogen of AP in most treated patients, the futility of attempts to determine the pathogen, which do not affect the result of treatment in any way [5], [6].

However, such admissions and the lack of objective data on the causative agents of AP do not mean a change in views on the role and place of antibiotics in medical care. These drugs continue to be considered as the basis of treatment, and a wide range of known pathogens of AP allows us to declare the special virulence of microbes in the event of treatment failure. In addition, the formation of the "microbial" concept of AP has led in recent years to the fact that bacterial forms of AP that do not have such obvious signs of infectious diseases as contagion and epidemic spread have become classified as an infectious disease.

This short list of features of AP treatment allows us to present the dominant views on the problem and principles of medical care in modern medicine on the eve of a pandemic. To this information, it is necessary to add such a fact as the indication of viruses along with bacteria among the most common pathogens of $\mathrm{AP}$, which has been constantly published in the literature for many years. However, the significance of viruses was mainly declarative, since such observations were relatively rare, and special antiviral treatment had more trials than practical applications.

But, on the other hand, the environment gave us clear signals about the approach of the viral era of inflammatory processes. The increase in the number of viral lung inflammations has become especially noticeable in the last couple of decades, which is quite consistent with long-term antibacterial therapeutic aggression and an increase in the share of viruses, as representatives of our microcosm, among the pathogens of AP. If we recall two fairly large coronavirus epidemics-SARS (2002-2004) and MERS (2012-2013), then it is not entirely correct to consider the pandemic as a complete surprise. To date, the similarity between the causative agents of these phenomena, which are designated as CoV, CoV-1 and CoV-2, respectively, has been proved [7]. Unfortunately, as the current situation shows, during the entire period after the first epidemic, no measures were developed or proposed that could help in the event of a repeat of the epidemic.

Now let's try to look at the sudden changes that are characteristic of the current coronavirus pandemic. First of all, the change in the epidemiological situation is an undoubted fact of novelty. The rapid spread of coronavirus in contact communication between people encourages the use of strict sanitary and quarantine measures and changes in the usual rhythm of life of entire countries.

Secondly, the most characteristic and severe lesion in coronavirus infection is pneumonia, which affects the same organ structures as the usual bacterial forms [1], [2]. The identity of morphological disorders generates the identity of functional shifts, so the descriptions of clinical signs of COVID-19 pneumonia and bacterial forms of AP differ in nuances, but do not have significant differences. However, memorized ideas about the complete dependence of AP on the pathogen are the reason that coronavirus lung damage is considered as an independent specific type of pathology.

Third, practical medicine has lost the former importance of antibiotics, but the change in the etiological features of AP has not actually affected the stereotypical ideas about the principles of treatment. Attempts are being made to use drugs that have been approved to treat other viral infections, but the results of these efforts are not yet encouraging. Although the search for antiviral drugs continues, old antibiotic-based AP treatment regimens are still being used. For the current period, up to $70-80 \%$ of patients with coronavirus receive antibiotics in the absence of direct indications for this and the previously known absence of an antiviral effect from their use [8], [9], [10].

Fourthly, one of the main topics of discussion on how to help patients with coronavirus pneumonia today is devoted to methods of support when signs of respiratory failure appear. Such support usually begins with the supply

International Journal of Research -GRANTHAALAYAH 
of oxygen, which is not a therapeutic method in itself and serves only a palliative and replacement role, and methods are proposed that can slightly enhance the effect of oxygenation. For example, breathing oxygen in the prone positioning [11], [12], [13], [14] or using a special cannula [15]. At the same time, it is recommended to carefully select the optimal time for intubation of the patient [16], and since the number of applicants for auxiliary ventilation has increased since the beginning of the pandemic, there are proposals to increase the production of necessary devices [17]. If we take into account the fact that this is the main effort of modern care for such patients, then this approach to the treatment of pneumonia should forget about the possibility of improving the final results.

Fifth, the materials of observations of large groups of people in the conditions of joint quarantine are very interesting and useful for forming new views on the problem [18], [19]. The data obtained showed that infection with coronavirus does not necessarily end with the disease. Up to $80 \%$ or more of those infected remain asymptomatic carriers, and among patients there is a wide range of clinical manifestations from barely noticeable signs to the development of terminal conditions. It should be emphasized that we are talking about infection with a single pathogen and the explanation of such clinical differences by special virulence will not be entirely correct. This phenomenon is not new, has long been known and has other explanations.

Finally, it is very interesting and even necessary to look at the information support of the current pandemic. Each of us, viewing daily news reports, unwittingly receives information about the number of infected, sick and dead from coronavirus infection. This information is constantly updated, and the replicated results leave a lasting impression with their scale. To date, the number of infected people in the world has already exceeded 44 million, and the number of deaths is approaching 1.2 million.

Such statistics are unusual and extreme even for many members of the medical profession and cause public concern, since each figure is the fate of a particular person. However, to understand the negative consequences of such information, it should be compared with statistics from similar and comparable situations. For example, just over a decade ago, there were about 450 million cases of AP per year worldwide, of which about 4 million were fatal [20], [21], and these figures have not changed significantly in subsequent years. Note that the overall figure reflects those who are sick, not infected, as in the current pandemic. Despite these truly tragic indicators, such statistics are little known even in medical circles, let alone in their daily coverage.

In this context, we are only talking about the medical aspects of the problem under discussion, so it is not entirely logical to be distracted by assessing the reasons for such a powerful attack on the formation of public opinion through the media. However, this fact in itself deserves a separate analysis of specialists working in this direction.

Understanding the specifics of modern medical care in COVID-19 allows us to at least outline the role of health systems in shaping treatment outcomes. The spread of infection depends primarily on the literacy and civic responsibility of the population, which in different parts of the world receives equivalent recommendations for strict sanitary and epidemiological measures, but the degree of compliance with these rules varies, which leads to the need for quarantine. Other methods of prevention have not yet been proposed by medicine, and vaccination of the population is still under development. It is likely that the number of infected people is significantly higher than recorded by statistics, since we are talking only about those who have been tested, and total verification is difficult to imagine even theoretically.

The fact that the vast majority of people infected with coronavirus do not get sick is a great gift of nature that is not directly related to any medical effort. Among patients with clinical symptoms of infection, most carry it relatively easily, despite the lack of specific effective care, especially since recognition of the ongoing search for such help can be found in almost every issue of specialized journals that discuss this topic. In this regard, it is illogical and incorrect to consider cured patients as the merit and success of medicine. This situation is very accurately reflected in the expression that came from ancient times and attributed to Galen, that nature itself treats most of its patients, without requiring recognition and gratitude for its results.

Thus, if we evaluate real medical care during a pandemic, we should frankly admit that the majority of infected and sick people overcome this test thanks to the capabilities of their own body. The use of maintenance and replacement therapy begins in the late stages of the disease, when the patient's condition begins to deteriorate catastrophically, and the direction of such efforts does not have a radical effect on the dynamics of the process. The principles of such care in clinical situations close to terminal conditions can no longer make a decisive change in the course of the disease, so the mortality rate in intensive care units reaches 25-50\% or higher [22], [23], [24].

Unlike patients who managed to survive viral aggression, most of the deceased are, in my opinion, on the conscience of medicine, which does not attach importance to timely and pathogenetically determined methods of treatment. Of course, among the dead there could be obviously hopeless observations, where the coronavirus 
complicated the course of concomitant serious diseases or affected people whose body, due to age regression, lost its former protective and compensatory capabilities. Such an assessment of known hopelessness can only be very conditional, since if the main mechanisms of the process were affected and the adaptation of the body was accelerated, the final result could be completely different, despite the aggravating factors.

The development of the section of pathogenetic care for AP is still hindered by the prevailing idea of the leading role of the pathogen and the importance of its suppression. This concept continues to rely on assumptions and analogies with other inflammatory processes, losing the unique differences between AP and diseases of other localization. At the same time, it is well known that a positive test for coronavirus does not mean the presence of pneumonia, the diagnosis of which is based only on the detection of a focus of inflammation in the lung. That is, the absolute sign of inflammation in the lungs is a lesion of the organ's tissues, and not just the presence of a virus in the body, isn't it?

In turn, this focus affects the blood flow of the pulmonary circulatory system and only after that, as a result of the discrepancy between the self-adaptation of the body and the speed of development of the process, there are synchronous violations of peripheral blood circulation. But it is generally accepted to monitor and correct circulatory disorders in AP by indicators of the periphery, not the lungs, right? If peripheral blood flow indicators are used for monitoring, it is necessary to take into account the fact that they have an inverse proportion to the pulmonary constants and are automatically regulated by the body.

The appearance of hypotension in AP is a sign of decompensation of circulatory shifts, as a result of the body's attempt to unload the pulmonary vessels, but in modern interpretation this signal is considered as a manifestation of septic shock, despite the absence of pathogens in the blood of the overwhelming number of such patients [25], [26], [27]. Now the same reason (septic shock in viral infection) explains such shifts in patients with COVID-19 [28]. This understanding of the mechanisms of the process in the lungs involves the inclusion of additional methods to increase peripheral pressure, instead of affecting its root causes. This misconception in assessing the causes and severity of the condition of patients plays, in my opinion, a fatal role in the fate of many of the dead.

This conclusion is based on the results of special studies with subsequent successful testing of pathogenetic treatment methods in the clinic. A detailed description of this work can be found in the recently published monograph: Igor Klepikov " Acute pneumonia. New doctrine and first treatment results " - ISBN (978-620-2-679176) $>$ \{https://www.cheapesttextbooks.com/IM/?keyval=ISBN+\%28978-620-2-67917-6\%29\}.

Today, there is a wide discussion on the issue of COVID-19 on the pages of medical publications, in which opinions sometimes appear about a new strategy for solving this problem. Unfortunately, conversations about the novelty of the strategy are actually replaced by various tactical proposals that do not affect the main idea of the essence of the task. The main and only cause of the problem is considered to be the pathogen and its spread, and the main goal of its solution is ways to neutralize it. Such facts as the different degree of manifestation of the same type of coronavirus infection in different people, as well as the pathogenesis of severe and terminal conditions in it, remain without due attention.

One of the signs of a crisis in solving this problem is attempts to find and explain the reasons for medical failures by the incompetence of political leaders [29]. This statement indirectly indicates that the authors are absolutely confident in the perfection of therapeutic efforts of modern medicine to help patients with CoV-2. According to the published text, it turns out that the cause of death of patients with coronavirus is state policy, and not any defects in the provision of medical care (see above). In this regard, it would be interesting to know why there is no direct correlation between the number of people infected with coronavirus, the percentage of deaths, and the political spectrum of different countries. It is a pity that the editorial Board of a prestigious journal, which should now be a leader in finding effective solutions to this problem, has taken such an unproductive position with the transfer of discussion of urgent medical problems to completely unprofessional ground.

Current statistics of the pandemic indicate that the spread of coronavirus is quite aggressive and fast, slowing down, but not stopping, even in conditions of quarantine and compliance with sanitary and anti-epidemic measures. At the same time, the rate of morbidity and mortality among infected people is relatively low, compared to many dangerous infections, which does not fit into the previously expressed suspicions about COVID-19 as a biological weapon. In addition, the appearance of information about the lack of stable and long-term immunity in patients who have had COVID-19, as well as cases of repeated diseases, is an indirect sign that the expected vaccination may not fully achieve its goal and that this infection may continue its further movement.

At the moment, all eyes are on the developers of vaccines and antiviral drugs, the creation and use of which is expected to be a major turning point in the fight against coronavirus. However, these expectations are based on plans 
and assumptions, the timing and success of which is still difficult to predict. At the same time, there is a group of patients who are in urgent need of not only supportive, but also pathogenetic treatment. Will these patients timely and effective assistance, depends not so much on the practitioners of medicine who strictly follow established guidelines and operate within acceptable regimens, but from professionals, influencing the formation of ideologies and ways of solving problems in modern health systems.

The near future will show us whether there are progressive leaders among modern medical specialists who can bring the system of views on the nature of AP in line with the fundamental provisions of medical science and determine a set of treatment methods that can influence the mechanisms of disease development, and not only the factors that contribute to its occurrence. Only then will real conditions be created for effective care of patients with inflammation of the lung tissue, most of whom will be able to avoid critical situations.

\section{SOURCES OF FUNDING}

This research received no specific grant from any funding agency in the public, commercial, or not-for-profit sectors.

\section{CONFLICT OF INTEREST}

The author have declared that no competing interests exist.

\section{ACKNOWLEDGMENT}

None.

\section{REFERENCES}

[1] Zhe Xu, Lei Shi, Yijin Wang at al. (2020). Pathological findings of COVID-19 associated with acute respiratory distress syndrome. The Lancet Respiratory Medicine, 2020, Vol 8, Issue 4, P420-422, APRIL 01, 2020

[2] M. Ackermann, S. E. Verleden, M. Kuehnel at al. (2020). Pulmonary Vascular Endothelialitis, Thrombosis, and Angiogenesis in Covid-19. May 21, 2020. DOI: 10.1056/NEJMoa2015432

[3] Feigin R (2004). Textbook of Pediatric Infectious Diseases (5th ed.). Philadelphia: W. B. Saunders. p. 299. ISBN 978-0-7216-9329-3.

[4] Lipman M, Chambers RC, Singer M, et al. (2020). SARS-CoV-2 pandemic: clinical picture of COVID-19 and implications for research. Thorax 2020; 75:614-616.

[5] J. P. Metlay, G. W. Waterer, A. C. Long at al.; on behalf of the American Thoracic Society and Infectious Diseases Society of America. "Diagnosis and Treatment of Adults with Community-acquired Pneumonia. An Official Clinical Practice Guideline of the American Thoracic Society and Infectious Diseases Society of America". American Journal of Respiratory and Critical Care Medicine, Volume 200, Issue 7, 1 October 2019, Pages e45e67, https://www.atsjournals.org/doi/full/10.1164/rccm.201908-1581ST

[6] Paula Peyrani, Lionel Mandell, Antoni Torres \& Glenn S Tillotson (2019) The burden of community-acquired bacterial pneumonia in the era of antibiotic resistance, Expert Review of Respiratory Medicine, 13:2, 139-152, DOI: $10.1080 / 17476348.2019 .1562339$

[7] https://en.wikipedia.org/wiki/Severe_acute_respiratory_syndrome

[8] Rawson TM, Moore LSP, Zhu N, et al. (2020). Bacterial and fungal co-infection in individuals with coronavirus: A rapid review to support COVID-19 antimicrobial prescribing [published online ahead of print, 2020 May 2]. Clin Infect Dis. 2020; ciaa530. doi:10.1093/cid/ciaa530

[9] Beović, M. Doušak, J. Ferreira-Coimbra et al. (2020). Antibiotic use in patients with COVID-19: a 'snapshot' Infectious Diseases International Research Initiative (ID-IRI) survey. Journal of Antimicrobial Chemotherapy, dkaa326, https://doi.org/10.1093/jac/dkaa326

[10] Kim D, Quinn J, Pinsky B et al. (2020). Rates of co-infection between SARS-CoV-2 and other respiratory pathogens. JAMA 2020; 323: 2085-6. 
[11] Renato Seligman and Beatriz Graeff Santos Seligman (2020). "Pandemic in the 21st Century. The Challenge of COVID-19". EC Pulmonology and Respiratory Medicine 9.8 (2020): 30-31.

[12] Koeckerling D, Barker J, Mudalige NL, et al.(2020). Awake prone positioning in COVID-19. Thorax Published Online First: 16 June 2020. doi: 10.1136/thoraxjnl-2020-215133

[13] Thompson AE et al. (2020) Prone positioning in awake, nonintubated patients with COVID-19 hypoxemic respiratory failure. JAMA Intern $\quad$ Med $2020 \quad$ Jun $17 ; \quad$ [e-pub]. (https://doi.org/10.1001/jamainternmed.2020.3030)

[14] Winearls S, Swingwood EL, Hardaker CL, et al. (2020). Early conscious prone positioning in patients with COVID-19 receiving continuous positive airway pressure: a retrospective analysis. BMJ, Open Respiratory Research, 2020;7:e000711. doi: 10.1136/bmjresp-2020-000711

[15] Vianello A, Arcaro G, Molena B, et al. (2020). High-flow nasal cannula oxygen therapy to treat patients with hypoxemic acute respiratory failure consequent to SARS-CoV-2 infection. Thorax. Published Online First: 23 July 2020. doi: 10.1136/thoraxjnl-2020-214993

[16] D. A. Berlin, R. M. Gulick, F. J. Martinez (2020). Severe Covid-19. NEJM, May 15, 2020, D0I: 10.1056/NEJMcp2009575

[17] M. L. Ranney, V. Griffeth, A. K. Jha (2020). Critical Supply Shortages - The Need for Ventilators and Personal Protective Equipment during the Covid-19 Pandemic. NEJM, 2020; 382:e41 DOI: 10.1056/NEJMp2006141

[18] Keeley AJ, Evans CM, de Silva TI (2020). Asymptomatic SARS-CoV-2 infection: the tip or the iceberg? Thorax 2020;75:621-622.

[19] Ing AJ, Cocks C, Green JP (2020). COVID-19: in the footsteps of Ernest Shackleton. Thorax, 2020;75:693-694.

[20] Rudan I, Boschi-Pinto C, Biloglav Z, Mulholland K, Campbell H. Epidemiology and etiology of childhood pneumonia. Bull World Health Organ. 2008; 86:408-416. [PMC free article] [PubMed] [Google Scholar]

[21] WHO Revised global burden of disease 2002 estimates. 2004. http://www.who.int/healthinfo/global_burden_disease/estimates_regional_2002_revised/en/ (accessed Nov 5, 2010).

[22] Renato Seligman and Beatriz Graeff Santos Seligman. "Pandemic in the 21st Century. The Challenge of COVID19". EC Pulmonology and Respiratory Medicine 9.8 (2020): 30-31.

[23] Grasselli G et al. Baseline characteristics and outcomes of 1591 patients infected with SARS-CoV-2 admitted to ICUs of the Lombardy region, Italy. JAMA 2020 Apr 6; [e-pub]. (https://doi.org/10.1001/jama.2020.5394)

[24] S. Richardson, J. S. Hirsch, M. Narasimhan at al. (2020). Presenting Characteristics, Comorbidities, and Outcomes Among 5700 Patients Hospitalized With COVID-19 in the New York City Area. JAMA. Published online April 22, 2020. doi:10.1001/jama.2020.6775

[25] Weiss SL, Fitzgerald JC, Pappachan J, et al.; Sepsis Prevalence, Outcomes, and Therapies (SPROUT) Study Investigators and Pediatric Acute Lung Injury and Sepsis Investigators (PALISI) Network: Global epidemiology of pediatric severe sepsis: The sepsis prevalence, outcomes, and therapies study. Am J Respir Crit Care Med 2015; 191:1147-1157

[26] AJ Morgan, AJ Glossop. Severe community-acquired pneumonia (2016). BJA Education, Volume 16, issue 5, may 1, 2016, pp. 167-172,https://doi.org/10.1093/bjaed/mkv052

[27] Garcia-Vidal C, Ardanuy C, Tubau F, et al. (2010). Pneumococcal pneumonia presenting with septic shock: host- and pathogen-related factors and outcomes. Thorax 2010; 65:77-81.

[28] Alhazzani W et al. Surviving sepsis campaign: Guidelines on the management of critically ill adults with coronavirus disease 2019 (COVID-19). Crit Care Med 2020 Mar 27; [e-pub]. (https://doi.org/10.1097/CCM.0000000000004363)

[29] Editorial from The New England Journal of Medicine (2020). Dying in a Leadership Vacuum. N Engl J Med 2020; 383:1479-1480. DOI: 10.1056/NEJM, e2029812 